\title{
The Association between the Risk of Cardiovascular Disease and Androgen Deprivation Therapy in Patients with Prostate Cancer. A Meta-Analysis and systematic review.
}

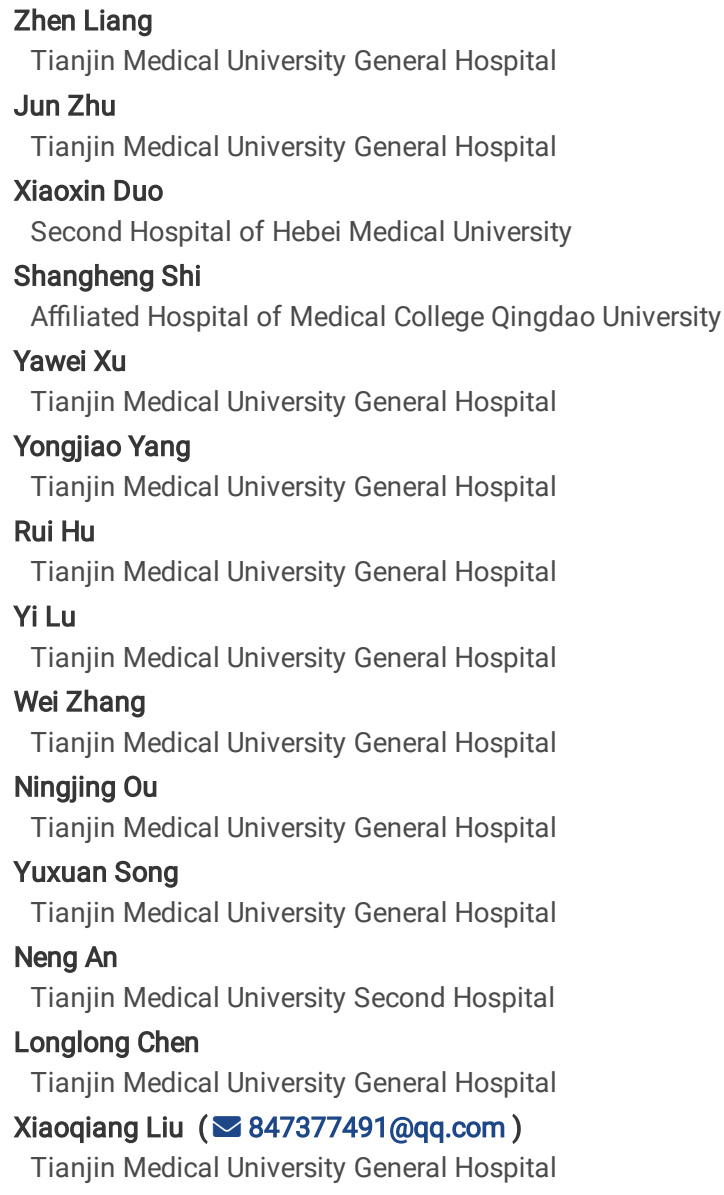

\section{Research article}

Keywords: prostate cancer, Androgen deprivation therapy (ADT), cardivascular disease (CVD)

Posted Date: October 25th, 2019

DOI: https://doi.org/10.21203/rs.2.10884/v3

License: @ (i) This work is licensed under a Creative Commons Attribution 4.0 International License. Read Full License

Version of Record: A version of this preprint was published at Andrology on December 17th, 2019. See the published version at https://doi.org/10.1111/andr.12731. 


\section{Abstract}

Background : Androgen deprivation therapy (ADT) is widely being applied in men who suffered from prostate cancer, our aim is to evaluate whether ADT is associated with an excess risk of cardiovascular disease (CVD). Method : Studies comparing the the incidence of CVD between ADT group and control group were identified through literature search in electronic databases (Pubmed, Embase, Web of Science) until July 2019 and only observational studies and randomized controlled trials (RCT) were included. The estimating relative risk ratio (RR) and 95\% confidence intervals (Cl) were calculated through random effects meta-analyses. Result : A statistically significant association was detected for acute myocardial infarction (AMI) with RR = $1.22 ; 95 \%$ confidence interval $\mathrm{Cl}, 1.05-1.43 ; \mathrm{P}<0.05$. Significant relationship between coronary heart disease (CHD) and ADT was also observed, with summary RR=1.19; $95 \% \mathrm{Cl}, 1.03-1.38 ; \mathrm{P}<0.05$. ADT was associated with a risk increasement for heart failure (HF) with $\mathrm{RR}=1.15 ; 95 \% \mathrm{Cl} 1.01-1.33$; $\mathrm{P}<0.05$. On the contrary, $\mathrm{ADT}$ was not associated with an increased risk of sudden cardiac death (SCD). Conclusions : From this study, ADT is associated with increased risk of AMI, CHD, and heart failure (HF); in contrast, this association is not detected in SCD; various modalities of ADT could significantly increase the risk of CHD, AMI, except for oral anti-androgen (AA). Our meta-analysis also suggests that the long-term application of ADT in prostate cancer patients would not result in a significant increase in AMI incidence compared with short-term. Moreover, the combined application of AA and GnRH agonists would lead to a similar risk of AMl compared with orchiectomy or GnRH agonists monotherapy whereas higher risk of CHD was detected when compared GnRH agonists plus AA with orchiectomy.

\section{Background}

Prostate cancer ( $\mathrm{PCa}$ ) has become the most common cancer in male and its growing trend in morbidity and mortality has been reported not only in western countries, but also in Asian countries, particularly in the northeast regions [1-3]. Since testosterone has been proved could accelerate the progression of prostate cancer, androgen deprivation therapy (ADT) is regarded as the basic treatment for PCa patients $[4,5]$. Unfortunately, its adverse impact on cardiovascular system is still controversial. In a recent study, Mottillo et al. [6] indicated that men with prostate cancer treated by ADT had a $21 \%$ higher risk of cardiovascular disease (CVD) than the same-age men. However, when focusing on different ADT modalities, results from former studies demonstrated high heterogeneity in the risk of cardiac disorders.

Recently, Zhao et al. [7] carried out a meta-analysis of prospective studies evaluating the connection between ADT and CVD risk. However, the investigators did not make a direct comparison among each ADT method; in addition, acute myocardial infarction (AMI), heart failure (HF) were not separated from CVD as individual endpoints. Therefore, the present study performed a systematic review to address the relationship between ADT for AMI, coronary heart disease (CHD), HF and sudden cardiac death (SCD) respectively.

\section{Methods}

\subsection{Study selection}

The research methodology of this study was performed based on the Preferred Reporting Items for Systematic Reviews and Meta-Analyses statement PRISMA statement[8] for reporting systematic reviews and meta-analyses to investigate the potential risk of CVD during the ADT treatment. Databases including the PUBMED, EMBASE, Web of Science were searched to identify studies in comparison with the use of ADT and any other control intervention on their impact on cardiovascular system. All databases were searched from inception to April 1, 2018 by two independent investigators ( $\mathrm{ZL}$ and RH). Disagreements were resolved by discussion with a third author $(\mathrm{XL})$. The search was conducted in English language with the search string: (prostate cancer OR prostate tumor OR prostate carcinoma) AND (androgen deprivation OR androgen suppression OR endocrine treatment) AND (cardiovascular OR myocardial infarction OR coronary heart disease OR congestive heart failure OR cardiac death OR heart disease) for Pubmed database and it was modified slightly to fit others. The abstracts of these articles identified by keyword searching were then screened, and went through full texts examination if they fit our criteria (as detailed below). There were no restrictions based on publication status. Searches of the included study reference lists were also performed manually to retrieve all relevant data.

The PICO research question was: Whether patients with prostate caner (Population), treated by ADT (Intervention) compared to placebo (Comparison intervention) suffer from higher risk of CVD (Outcome), in observational and RCT studies (Study design)

Studies were regarded eligible if they (1) designed as observation study or randomized controlled trial (RCT) study; (2) the research object is cardiovascular disease with AMI, CHD, HF or SCD as endpoint; (3) with sufficient data for analysis; (4) ADT type was prespecified and ADT duration was more than 6 months; (5) patients with baseline cardiac comorbidities were separated. All screening process was accomplished with the bibliographic software EndNote X9 (Clarivate Analytics)

\subsection{Quality Assessment and Data extraction}

All included observational studies were evaluated for risk of bias by two reviewers (ZL and RH) through Newcastle Ottawa Scale (NOS) [9] with $\geq 7$ score representing high-quality while the assessment for RCT studies was based on Cochrane Collaboration's tool for risk of bias [10]. RCTs were evaluated in terms of : Random sequence generation, Allocation concealment (Selection bias); Blinding of participants and personnel (Performance bias); Blinding of outcome assessment (Detection bias); Incomplete outcome data (Attrition bias); Selective reporting (Reporting bias); Anything else, ideally prespecified (Other bias). There are three levels: low, unclear, or high risk for the quality of RCT evidence. The quality evaluation was carried out by two independent reviewers (ZL and $\mathrm{SS}$ ), and a third reviewer was consulted to adjudicate any disagreements (YY). Data were extracted by two researchers (ZL and NA) independently to minimize the bias. The following data were extracted: 
1. Basic information about study (total number of participants, number of ADT users, number of control group, follow-up duration, treatment method, definition of CVD )

2. Study elements (first author, median age, country/region, year, design).

3. experimental results ( outcomes measure and quantity of $\mathrm{AMI}, \mathrm{CHD}, \mathrm{HF}$ and SCD)

\subsection{Statistical Analysis and Subgroups Analyses}

The heterogeneity of included studies was evaluated using the Cochrane $\mathrm{I}^{2}$ statistics as well as a "remove-one" analysis. P $<0.05$ was defined as invalid assumption of homogeneity. A frequentist meta-analysis according to random effects model was performed for all outcomes to assess relative risk (RR) and their $95 \%$ confidence interval $(95 \% \mathrm{Cl})$ using the method of the Mantel-Haenszel test. The outcomes were then presented as forest plots. The data analysis was accomplished through STATA version 14.0 and Review Manager (version5.2; the Cochrane Collaboration, Oxford, United Kingdom). Subgroup analyses were carried out based on the various types of ADT (e.g. GnRH agonists, AA, GnRH agonists +AA and Orchiectomy) vs non-ADT and the ADT duration ( $\leq 5$ year or $>5$ year). Funnel plot was used to evaluate the publication bias, with $\mathrm{P}<0.05$ suggesting publication bias [11].

\section{Results}

\subsection{Literature Search and Characteristics}

Figure 1 represents a flowchart demonstrated the selection process that met our criteria aforementioned, a total of 1541 potential records were initially identified from databases through the search terms listed above. 531 duplicate studies were excluded. 50 were considered closely correlated to the concept of this study and underwent full text review. 14 studies were removed because they did not mention AMI, CHD, HF or SCD separately as outcomes. 2 were excluded due to insufficient data, 7 studies were excluded because ADT duration was shorter than 6 months, 6 did not specifically report the type of ADT. Additionally, we remove 9 retrospective researches from our study, 2 were excluded for using the same databases as studies that were already included. In the end, 8 studies [12-19] consisted of 316,111 patients were included in our meta-analysis of AMI, 7 studies [13-16, 19-21] involving 532,919 patients were identified in the CHD analysis, data from 6 studies [12, 13, 15-17, 20] with 334,093 patients were available in the HF analysis, 5 studies [12, 14, 22-24] containing 182,403 patients were included in the SCD analysis. No additional articles were eligible for meta-analysis through reference searching.

The basic characteristics of included studies are provided in table 1. All studies were published from 2011 to 2017 . Quality evaluation for observational studies indicated no studies being of low quality in all domains of the Newcastle-Ottawa score. The methodological quality of all RCT studies was shown in Figure 2 and no research was excluded due to low quality. According to the Beggs' funnel plot, the likelihood of publication bias was low, with a p value of 0.097 for the slope coefficient. (Figure 3) The "remove-one" analysis did not demonstrated influences of one specific study.

\subsection{Association between ADT and AMI}

8 studies were regarding the relationship between ADT and AMI.

Data from 4 studies with 142,012 ADT users and 174,099 non-ADT users were suitable for AA [13, 16, 17, 19] subgroup-analysis; 3 [13, 16, 19] for GnRH agonists plus $A A, 4[13,14,16,19]$ for $\mathrm{GnRH}$ agonists and $5[13,14,16,18,19]$ for orchiectomy. According to our results illustrated in Figure 4 , AMI was statistically significant to ADT application $(R R=1.22 ; 95 \% \mathrm{Cl}, 1.05-1.43 ; \mathrm{P}<0.05)$ with $A A(R R=1.34 ; 95 \% \mathrm{Cl}, 1.07-1.69 ; \mathrm{P}<0.05)$; orchiectomy $(\mathrm{RR}=1.71$; 95\% Cl, 1.03-2.83; $\mathrm{P}<0.05)$; GnRH agonists ( $R R=1.66 ; 95 \% \mathrm{Cl}, 1.01-2.72 ; \mathrm{P}<0.05) ; \mathrm{GnRH}$ agonists plus $\mathrm{AA}(\mathrm{RR}=2.74 ; 95 \% \mathrm{Cl}, 1.67-4.48 ; \mathrm{P}<0.05)$; respectively. (Figure 5) It is apparent that no statistically significant difference was detected between GnRH agonists plus $A A$ and other $A D T$ method in causing $\mathrm{AMI}$, except for $\mathrm{AA}(\mathrm{AA}: \mathrm{P}<0.05$; orchiectomy: $\mathrm{P}=0.19$; $\mathrm{GnRH}$ agonists: $\mathrm{P}=0.16)$. (Figure 6)

\subsection{Association between ADT and CHD}

There were a total of 532,919 participants from all the 7 included studies investigating the relationship between ADT and CHD of which 157,165 received ADT and 375,754 were control groups. A significantly increased CHD risk was found in the prostate cancer patients treated with $A D T$. (RR=1.19; $95 \% \mathrm{Cl}$ : 1.03-1.38); (Figure 7). Subgroup analyses by ADT type showed that each type of ADT correlated to $C H D$, with orchiectomy $(\mathrm{RR}=1.13 ; 95 \% \mathrm{Cl}, 1.08-1.18 ; \mathrm{P}<0.05) ; \mathrm{GnRH}$ agonists $(\mathrm{RR}=1.98 ; 95 \% \mathrm{Cl}, 1.01-3.92 ; \mathrm{P}<0.05) \mathrm{GnRH}$ agonists plus $\mathrm{AA}(\mathrm{RR}=2.77 ; 95 \% \mathrm{Cl} 1.65-4.66 ; \mathrm{P}<0.05)$; respectively, except for $\mathrm{AA}(\mathrm{RR}=1.34 ; 95 \% \mathrm{Cl}$, 0.59-3.05; $P<0.05$ ); (Figure 8) Compared with orchiectomy, GnRH agonists plus AA could significantly increase the risk of $C H D(P<0.05)$, while similar risk of $\mathrm{CHD}$ was seen when compared $\mathrm{GnRH}$ agonists plus $\mathrm{AA}$ with $\mathrm{GnRH}$ agonists alone with $\mathrm{P}$ value $=0.45$. (Figure 9)

\subsection{Association between ADT and SCD HF}

Subgroup analyses of the relationship between ADT and SCD were also investigated with total of 182,403 identified events from 5 studies, among them 79,881 were ADT users and 102,522 were from control groups. We identified that SCD was not significantly associated with $A D T$ usage. (RR=1.13; $95 \%$ C 0.89-1.45; $P<0.05$ ). (Figure 10) Subgroup analysis for different types of ADT was not performed as there was only one study [14] reported exact ADT method. Figure 11 showed the forest plot of HF for patients with or without ADT treatment. Pooled data for HF were available from 6 studies with a total of 334,093 patients $(97,925$ with ADT exposure and 236,168 without ADT exposure). Based on our results, ADT was associated with a higher incidence of HF compared to control group. (RR=1.15; $95 \% \mathrm{Cl} 1.01-1.33$; $\mathrm{P}<0.05)$. Subgroup analysis was also not performed for ADT type because of the small number of trials that reported such outcomes.

\subsection{Subgroup by duration of ADT}


In order to reduce the impact of inconsistent endpoints on our conclusion, whether the duration of ADT application was associated with a significant effect on the risk of AMI events was also explored. The included studies were separated into different groups based on the duration of ADT application, and we defined 5 year as the cut-off value. 3 studies $[12,14,17]$ with 53,115 cases and 53,124 controls were in subgroup with ADT application more than 5 years, and others were in subgroup with ADT application less than 5 years. Pool results of our subgroup meta-analysis revealed patients from $>5$ group have similar risk of AMI compared with $\leq 5$ which means our results were not affected by different follow up when regarding 5 year as cut-off value. (RR $=1.35,95 \% \mathrm{Cl}, 1.00-1.82$, $\mathrm{P}=0.05$, for $\leq 5$ year group) ( $\mathrm{RR}=1.31,95 \% \mathrm{Cl}$ : $0.66-2.63, \mathrm{P}=0.44$ for $>5$ year group). (Figure 12$)$ As for the $\mathrm{CHD}, \mathrm{HF}$ and $\mathrm{SCD}$ group, the sum of included studies for each subgroup is quite limited thus the analysis was not conducted.

\section{Discussion}

The correlation between ADT and cardiovascular toxicity is a debatable topic in PCa treatment. Multiple researches explored this relationship with different outcomes.

Our results indicated that ADT was associated with a significant increase in risk of AMI, CHD, and HF, but not found to be associated with SCD; the individual administration of each type of ADT was associated with AMI and CHD, except for AA; AA alone was only significantly associated with the increased risk of AMI, but not CHD. In addition, using ADT more than 5 years would not lead to an increased risk of AMI compared with less than 5 years. Three previous researches are diverged with our results due to their small number of endpoints. Furthermore, multiple former studies illustrated that orchiectomy was not associated with $\mathrm{CHD}$ events $[25,26]$. This may attribute to their enrollment setting, men chose orchiectomy were older, suffered from more advanced stage of PCa and accompanied by more comorbidities, which in turn may affect the risk of CVD endpoints [27]. The distinction in inclusion criteria and duration of ADT may also lead to variation. Furthermore, three studies $[5,28,29]$ failed to detect a significant association between ADT and cardiovascular related death, due to the fact that the previous or later ADT users were not ruled out in control group.

ADT is the primary systemic therapy for prostate cancer and nearly half of patients received ADT during their disease course [30]. However, patients initiating ADT suffered from adverse effects including weight gain, insulin resistance, decreased libido, obesity, sarcopenia; as well as cerebrovascular events and metabolic syndrome (MetS) all of which could possibly be induced by deficiency of testosterone [31, 32]. MetS is a major public health challenge due to its effect on the progression of CVD, cardiac mortality and its high prevalence in general population [33]. Clinical features of MetS caused by ADT are different from classically-defined MetS in terms of high-density lipoprotein-C (HDL-C) response and fat accumulation, all of which could elevate triglycerides, blood pressure and glucose levels [34-36]. Such components would also accelerate atherosclerosis [37].

It has been suggested that maximal androgen blockade (MAB), in which surgical (orchiectomy) or medical castration (GnRH agonists) is combined with $\mathrm{AA}$ therapy, could improve clinical efficacy [38]. Based on our study, we found although the combined utilization of GnRH agonists and AA could increase the risk of cardiac adverse effects significantly, no significant difference was detected when compared GnRH agonists plus AA with the individual GnRH agonists in the risk of $\mathrm{AMI}$ and $\mathrm{CHD}$, but GnRH agonists plus AA was more likely to increase the risk of CHD compared with surgical castration or AA. Therefore, we could draw a conclusion that $\mathrm{GnRH}$ agonists, rather than $\mathrm{AA}$, may play a role in increasing risk of cardiac events in MAB therapy. A number of analyses have suggested that CVD was associated with GnRH agonists though its potential mechanism remained unclear. Several risk factors may contribute to the greater risk of CVD during GnRH agonists therapy such as hyperglycemia, dyslipidemia and obesity [39]. Furthermore, it has been proved that human heart tissue expresses the $\mathrm{GnRH}$ agonists receptor, and a basic study on rat heart tissue demonstrated that stimulating these receptors with $\mathrm{GnRH}$ agonists could cause progression in the contractility of the cardiomyocyte [40]. The promoting effect of GnRH agonists on atherosclerotic through boosting the development of metabolic complications seems to offer another plausible mechanism that could distinguish different forms of ADT in terms of associated CVD risk and hence is worthy of further exploration [30]. Our results revealed the combined application of AA and GnRH agonists had a similar risk of AMI and CHD compared with monotherapy ADT method, therefore, the combined application of AA and GnRH agonists is in prior position in terms of overall survival as the current EAU-ESTRO-SIOG guidelines [41, 42] recommended based on a large Cochrane review which compared different types of ADT and different dosages in subgroup analysis [43],

Multiple earlier studies have proved that GnRH agonists were associated with a higher risk of CVD compared with orchiectomy [44], whereas our study indicated orchiectomy monotherapy could also lead to cardiac events. Orchiectomy can lead to a low level of testosterone though it remains unclear how low testosterone levels causes major cardiovascular events. Callou de Sá et al. [44] indicated that men with CHD had higher oestradiol and free oestrogen index (FEI) levels. As a matter of fact, high level estrogen can increase heart attack risk by accelerating coagulation and platelet aggregation in coronary arteries [45]. A nationwide, population-based study, provided exclusive evidence to show that closed risk of fatal CVD was observed for men treated by GnRH agonists compared with orchiectomy[25]. Further, larger population-based trial is needed to determine whether interventions like orchiectomy that raise estrogen levels might promote the progression of CHD, so that clinical doctors could be conscious of the serious potential risks of orchiectomy and ensure medical safety when deciding the type of ADT for patients.

Our subgroup analysis for the duration of ADT indicated that long-term ADT was not associated with an excess risk of AMI when regarding 5 year as threshold. In an observational study, Efstathiou et al. [23] indicated that long-term ADT administration could not increase the risk of cardiovascular mortality compared with short-term in men with locally advanced PCa. In another study, patients from control group received short-term androgen suppression while patients who received 2-5 years of further treatment were recruited as experiment group, the result demonstrated that no significant difference was observed in overall mortality between short-term group and long-term group [22]. On the other hand, evidence from another more resent study suggested the

cardiovascular risk factors such as hyperglycemia, frank diabetes, and MetS are more likely to occur in patients with long-term ADT over 12 months, while with short-term ADT, (3-6 months) users are only affected by temporary insulin resistance [31]. Therefore, the optimum duration of ADT application should be adapted to comorbidities conditions and risk factors of individual patients. 
Based on our results, the administration of ADT was not associated with SCD, but led to an increased risk of HF. Several former analyses have investigated this relationship between SCD and ADT, and came up with very different results. Several studies showed that ADT could significantly improve prostate cancer-specific survival and overall survival $[5,46,47]$. On the other hand, Gandaglia et al. [14] indicated the usage of GnRH agonists was related to significantly increased risk of SCD in patients with non-metastatic PCa. This distinction could be accounted for the enrollment setting. Clinical trials usually enroll patients younger and healthier with lower risk level of cardiac morbidity and mortality. Further studies with more rational enrollment settings are needed to evaluate the benefits and risks of ADT. Although our results suggested that ADT was not related to an increased risk of cardiovascular mortality, many previous studies have suggested that patients treated by ADT have higher rates of non-cancer death compared with the general population because of diabetes or other adverse effects. Meng et al. [48] demonstrated in a recent meta-analysis that GnRH agonists alone, GnRH agonists plus AA and orchiectomy were significantly related to stroke in patients treated by ADT. This effect is noteworthy because it may reverse the survival benefit of ADT in men affected by PCa.

The previous literature also showed conflicting evidence evaluating the link between ADT and HF. Multiple previous studies revealed men treated with ADT were associated with significantly increased of fatal and nonfatal HF in all patients especially for those with pre-existing CVD which met our results [32]; whereas only one propensity-score matching cohort study from Canada demonstrated that incidence of HF was not higher among ADT users with HR= 0.95 ; $95 \% \mathrm{Cl}, 0.90-1.00$. Research which explored the impact of ADT on cardiomyocyte contractility at molecular level, and the results of testosterone therapy for HF at clinical level is needed to specify the possible relationship between HF and ADT.

This study has limitations. First, although we have strictly followed the PRISMA guidance, tried our best to apply the most extensive keywords and conducted the selection as impartial as possible, we know that some potential studies may still be neglected in our search, which would compromise our results. Second, the heterogeneity of our study was high, probably due to included studies used different criteria for patient recruitment, different defination of CHD, AMI, SCD, $\mathrm{HF}$ among studies and different treatment method for $\mathrm{PCa}$, and because they included disease of variable severity. We could not explore the source of the heterogeneity through subgroup analyses because of the limited quantity of included studies. However, the "remove-one" sensitivity analysis suggested that our findings are convincible. The funnel plot also indicated that there is no publication bias. Future studies should aim to recruit consecutive cases under ADT treatment with more detailed subgroup analysis and assess cardiac risk using standarlized instruments that have cross-centre validity. Third, our analysis pooled together both RCT and observational studies, and subgroup analyses based on study design were not performed in the AMI and CHD subgroup, because all the included studies are designed observationally for AMI and CHD subgroup. Fourth, some included studies do not provide direct data for analysis, so we have to calculate and extract the data we needed by ourselves, this may have an impact on the overall result to some extent.

\section{Conclusions}

Our analysis demonstrates an increased risk of CHD, AMI, HF for ADT application; ADT is not connected with SCD occurrence and it requires further exploration; various ADT modalities have different impact on CVD risk in different level, the combined application of AA and GnRH agonists would not significantly increase the risk of AMI compared with individual method; AA is less likely to trigger onset of CHD compared with other methods but would significantly lead to AMI. In addition, this study also reports that that short-term use and long-term use of ADT lead to similar risks of AMI. Therefore, ADT is connected with a significant negative impact on life quality. Cautions and periodic cardiovascular elevation are necessary for patients before the ADT starting. More experimental and epidemiological studies are needed to discriminate the SCD effects on different types of ADT.

\section{Declarations}

Ethics approval and consent to participate: Not applicable

Consent to publish: Not applicable

Availability of data: All data is included in the article and additional files.

Competing interests: The authors declare that there are no conflicts of interest.

Funding: This work was supported by the Zhao Yi-Cheng Medical Science Foundation of China (Tianjin ICP prepared No.15000470)

\section{Authors' contributions}

LZ and HR:Data analysis,project development,Manuscript writing

LX and RH:Data collection,project development,Manuscript editing

WZ and YL: Data analysis,Manuscript editing

YX and LC: Data collection,Project development

YS and YY: Data analysis

JZ and XD: Data collection of revised version

SS and NA: Data collection of revised version

Acknowledgments: Not applicable. 


\section{References}

1. Todua F, Gagua R, Maglakelidze M, Maglakelidze D: Cancer incidence and mortality - Major patterns in GLOBOCAN 2012, worldwide and Georgia, vol. 9; 2015.

2. Haas GP, Delongchamps N, Brawley OW, Wang CY, de la Roza G: The worldwide epidemiology of prostate cancer: perspectives from autopsy studies. The Canadian journal of urology 2008, 15(1):3866-3871.

3. Kimura T, Egawa S: Epidemiology of prostate cancer in Asian countries. International Journal of Urology $2018,25$.

4. Bolla M, Gonzalez D, Warde P, Dubois JB, Mirimanoff RO, Storme G, Bernier J, Kuten A, Sternberg C, Gil T et al: Improved survival in patients with locally advanced prostate cancer treated with radiotherapy and goserelin. The New England journal of medicine 1997, 337(5):295-300.

5. Messing EM, Manola J, Yao J, Kiernan M, Crawford D, Wilding G, di'SantAgnese PA, Trump D: Immediate versus deferred androgen deprivation treatment in patients with node-positive prostate cancer after radical prostatectomy and pelvic lymphadenectomy. The Lancet Oncology 2006, 7(6):472-479.

6. Mottillo S, Filion KB, Genest J, Joseph L, Pilote L, Poirier P, Rinfret S, Schiffrin EL, Eisenberg MJ: The metabolic syndrome and cardiovascular risk a systematic review and meta-analysis. Journal of the American College of Cardiology 2010, 56(14):1113-1132.

7. Zhao J, Zhu S, Sun L, Meng F, Zhao L, Zhao Y, Tian H, Li P, Niu Y: Androgen deprivation therapy for prostate cancer is associated with cardiovascular morbidity and mortality: a meta-analysis of population-based observational studies. PloS one 2014, 9(9):e107516.

8. Liberati A, Altman DG, Tetzlaff J, Mulrow C, Gotzsche PC, loannidis JP, Clarke M, Devereaux PJ, Kleijnen J, Moher D: The PRISMA statement for reporting systematic reviews and meta-analyses of studies that evaluate healthcare interventions: explanation and elaboration. BMJ (Clinical research ed) 2009 , 339:b2700.

9. Wells G, Shea B, O'Connell D, Peterson j, Welch V, Losos M, Tugwell P: The Newcastle-Ottawa Scale (NOS) for Assessing the Quality of Non-Randomized Studies in Meta-Analysis. $\square 2000, \square$.

10. Higgins JP, Altman DG, Gotzsche PC, Juni P, Moher D, Oxman AD, Savovic J, Schulz KF, Weeks L, Sterne JA: The Cochrane Collaboration's tool for assessing risk of bias in randomised trials. BMJ (Clinical research ed) 2011, 343:d5928.

11. Chaimani A, Higgins J, Mavridis D, Spyridonos P, Salanti G: Graphical tools for network meta-analysis in STATA. PloS one 2013, 8:e76654.

12. Alibhai SM, Duong-Hua M, Sutradhar R, Fleshner NE, Warde P, Cheung AM, Paszat LF: Impact of androgen deprivation therapy on cardiovascular disease and diabetes. Journal of clinical oncology : official journal of the American Society of Clinical Oncology 2009, 27(21):3452-3458.

13. Martin-Merino E, Johansson S, Morris T, Garcia Rodriguez LA: Androgen deprivation therapy and the risk of coronary heart disease and heart failure in patients with prostate cancer: a nested case-control study in UK primary care. Drug safety 2011, 34(11):1061-1077.

14. Gandaglia G, Sun M, Popa I, Schiffmann J, Abdollah F, Trinh QD: The impact of androgen-deprivation therapy (ADT) on the risk of cardiovascular (CV) events in patients with non-metastatic prostate cancer: a population-based study. 2014, 114(6b):E82-e89.

15. Haque R, UlcickasYood M, Xu X, Cassidy-Bushrow AE, Tsai HT, Keating NL, Van Den Eeden SK, Potosky AL: Cardiovascular disease risk and androgen deprivation therapy in patients with localised prostate cancer. a prospective cohort study. British journal of cancer 2017, 117(8):1233-1240.

16. Van Hemelrijck M, Garmo H, Holmberg L, Ingelsson E, Bratt O, Bill-Axelson A, Lambe M, Stattin P, Adolfsson J: Absolute and relative risk of cardiovascular disease in men with prostate cancer: results from the Population-Based PCBaSe Sweden. Journal of clinical oncology : official journal of the American Society of Clinical Oncology 2010, 28(21):3448-3456.

17. Iversen P, McLeod DG, See WA, Morris T, Armstrong J, Wirth MP: Antiandrogen monotherapy in patients with localized or locally advanced prostate cancer: final results from the bicalutamide Early Prostate Cancer programme at a median follow-up of 9.7 years. BJU international 2010, 105(8):1074-1081.

18. Jespersen CG, Norgaard M, Borre M: Androgen-deprivation therapy in treatment of prostate cancer and risk of myocardial infarction and stroke: a nationwide Danish population-based cohort study. European urology 2014, 65(4):704-709.

19. Keating NL, O'Malley A, Freedland SJ, Smith MR: Diabetes and cardiovascular disease during androgen deprivation therapy: observational study of veterans with prostate cancer. Journal of the National Cancer Institute 2012, 104(19):1518-1523.

20. O'Farrell S, Garmo H, Holmberg L, Adolfsson J, Stattin P, Van Hemelrijck M: Risk and timing of cardiovascular disease after androgen-deprivation therapy in men with prostate cancer. J Clin Oncol 2015, 33(11):1243-1251.

21. Robinson D, Garmo H, Lindahl B, Van Hemelrijck M, Adolfsson J, Bratt O, Holmberg L, Stattin P: Ischemic heart disease and stroke before and during endocrine treatment for prostate cancer in PCBaSe Sweden. International journal of cancer 2012, 130(2):478-487.

22. Bolla M, Van Tienhoven G, Warde P, Dubois JB, Mirimanoff RO, Storme G, Bernier J, Kuten A, Sternberg C, Billiet I et al: External irradiation with or without long-term androgen suppression for prostate cancer with high metastatic risk: 10-year results of an EORTC randomised study. Lancet Oncol 2010 , 11(11):1066-1073.

23. Efstathiou JA, Bae K, Shipley WU, Hanks GE, Pilepich MV, Sandler HM, Smith MR: Cardiovascular mortality after androgen deprivation therapy for locally advanced prostate cancer. RTOG 85-31. Journal of clinical oncology : official journal of the American Society of Clinical Oncology 2009, 27(1):92-99.

24. Roach M, 3rd, Bae K, Speight J, Wolkov HB, Rubin P, Lee RJ, Lawton C, Valicenti R, Grignon D, Pilepich MV: Short-term neoadjuvant androgen deprivation therapy and external-beam radiotherapy for locally advanced prostate cancer: long-term results of RTOG 8610. Journal of clinical oncology : official journal of the American Society of Clinical Oncology 2008, 26(4):585-591.

25. Thomsen FB, Sandin F, Garmo H, Lissbrant IF, Ahlgren G, Van Hemelrijck M, Adolfsson J, Robinson D, Stattin P: Gonadotropin-releasing Hormone Agonists, Orchiectomy, and Risk of Cardiovascular Disease: Semi-ecologic, Nationwide, Population-based Study. European urology 2017, $72(6): 920-928$.

26. Stamatiou K, Stamatopoulou E, Christopoulos G: Is bilateral orchiectomy for metastatic prostate cancer treatment associated with high cardiovascular risk? Aging and disease 2013, 4(6):381-384.

Page 6/15 
27. Mikkola A, Aro J, Rannikko S, Ruutu M: Ten-year survival and cardiovascular mortality in patients with advanced prostate cancer primarily treated by intramuscular polyestradiol phosphate or orchiectomy. The Prostate 2007, 67(4):447-455.

28. Soloway MS, Hachiya T, Ruiz HE, Gomez CC, Civantos F: Significance of androgen deprivation prior to radical prostatectomy, with special reference to prostate-specific antigen. World journal of urology 1993, 11(4):221-226.

29. Hedlund PO, Ala-Opas M, Brekkan E, Damber JE, Damber L, Hagerman I, Haukaas S, Henriksson P, Iversen P, Pousette A et al: Parenteral estrogen versus combined androgen deprivation in the treatment of metastatic prostatic cancer - Scandinavian Prostatic Cancer Group (SPCG) Study No. 5. Scandinavian journal of urology and nephrology 2002, 36(6):405-413.

30. Conteduca V, Di Lorenzo G, Tartarone A, Aieta M: The cardiovascular risk of gonadotropin releasing hormone agonists in men with prostate cancer: an unresolved controversy. Critical reviews in oncology/hematology 2013, 86(1):42-51.

31. Saylor PJ, Smith MR: Metabolic complications of androgen deprivation therapy for prostate cancer. The Journal of urology 2009, 181(5):1998-2006; discussion 2007-1998.

32. Elagizi A, Kohler TS, Lavie CJ: Testosterone and Cardiovascular Health. Mayo Clinic proceedings 2018, 93(1):83-100.

33. Hoffman EL, VonWald T, Hansen K: The metabolic syndrome. South Dakota medicine : the journal of the South Dakota State Medical Association 2015, Spec No:24-28.

34. Braga-Basaria M, Dobs AS, Muller DC, Carducci MA, John M, Egan J, Basaria S: Metabolic syndrome in men with prostate cancer undergoing long-term androgen-deprivation therapy. Journal of clinical oncology : official journal of the American Society of Clinical Oncology 2006, 24(24):3979-3983.

35. Mitsuzuka K, Kyan A, Sato T, Orikasa K, Miyazato M, Aoki H, Kakoi N, Narita S, Koie T, Namima T et al: Influence of 1 year of androgen deprivation therapy on lipid and glucose metabolism and fat accumulation in Japanese patients with prostate cancer. Prostate cancer and prostatic diseases 2016, 19(1):5762.

36. Sieminska L, Wojciechowska C, Walczak K, Borowski A, Marek B, Nowak M, Kajdaniuk D, Foltyn W, Kos-Kudla B: Associations between metabolic syndrome, serum thyrotropin, and thyroid antibodies status in postmenopausal women, and the role of interleukin-6. Endokrynologia Polska 2015, 66(5):394-403.

37. Korkmaz H, Canayaz E, Birtane S, Altikardes A: Fuzzy logic based risk assessment system giving individualized advice for metabolic syndrome and fatal cardiovascular diseases. Technology and health care : official journal of the European Society for Engineering and Medicine 2019.

38. Bennett CL, Tosteson TD, Schmitt B, Weinberg PD, Ernstoff MS, Ross SD: Maximum androgen-blockade with medical or surgical castration in advanced prostate cancer: A meta-analysis of nine published randomized controlled trials and $\mathbf{4 1 2 8}$ patients using flutamide. Prostate cancer and prostatic diseases 1999, 2(1):4-8.

39. Poljak Z, Hulin I, Maruscakova L, Mladosievicova B: Are GnRH and FSH potentially damaging factors in the cardiovascular system? Die Pharmazie 2018, 73(4):187-190

40. Dong F, Skinner DC, Wu TJ, Ren J: The heart: a novel gonadotrophin-releasing hormone target. Journal of neuroendocrinology 2011, 23(5):456-463.

41. Mottet N, Bellmunt J, Bolla M, Briers E, Cumberbatch MG, De Santis M, Fossati N, Gross T, Henry AM, Joniau S et al: EAU-ESTRO-SIOG Guidelines on Prostate Cancer. Part 1: Screening, Diagnosis, and Local Treatment with Curative Intent. European urology 2017, 71(4):618-629.

42. Cornford P, Bellmunt J, Bolla M, Briers E, De Santis M, Gross T, Henry AM, Joniau S, Lam TB, Mason MD et al: EAU-ESTRO-SIOG Guidelines on Prostate Cancer. Part II: Treatment of Relapsing, Metastatic, and Castration-Resistant Prostate Cancer. European urology 2017, 71(4):630-642.

43. Kunath F, Grobe HR, Rucker G, Motschall E, Antes G, Dahm P, Wullich B, Meerpohl JJ: Non-steroidal antiandrogen monotherapy compared with luteinizing hormone-releasing hormone agonists or surgical castration monotherapy for advanced prostate cancer: a Cochrane systematic review. BJU international 2015, 116(1):30-36.

44. Callou de Sa EQ, Feijo de Sa FC, e Silva Rde S, de Oliveira KC, Guedes AD, Feres F, Verreschi IT: Endogenous oestradiol but not testosterone is related to coronary artery disease in men. Clinical endocrinology 2011, 75(2):177-183.

45. Mohamad MJ, Mohammad MA, Karayyem M, Hairi A, Hader AA: Serum levels of sex hormones in men with acute myocardial infarction. Neuro endocrinology letters 2007, 28(2):182-186.

46. Bolla M, Collette L, Blank L, Warde P, Dubois JB, Mirimanoff RO, Storme G, Bernier J, Kuten A, Sternberg C et al: Long-term results with immediate androgen suppression and extemal irradiation in patients with locally advanced prostate cancer (an EORTC study): a phase III randomised trial. Lancet (London, England) 2002, 360(9327):103-106.

47. Pilepich MV, Winter K, Lawton CA, Krisch RE, Wolkov HB, Movsas B, Hug EB, Asbell SO, Grignon D: Androgen suppression adjuvant to definitive radiotherapy in prostate carcinoma-long-term results of phase III RTOG 85-31. International journal of radiation oncology, biology, physics 2005, 61(5):1285-1290.

48. Meng F, Zhu S, Zhao J, Vados L, Wang L, Zhao Y, Zhao D, Niu Y: Stroke related to androgen deprivation therapy for prostate cancer: a meta-analysis and systematic review. BMC cancer 2016, 16:180.

\section{Tables}

Table 1. Characteristics of randomized included studies 


\begin{tabular}{|c|c|c|c|c|c|c|c|c|c|}
\hline $\begin{array}{l}\text { First } \\
\text { author }\end{array}$ & year & $\begin{array}{l}\text { Types of } \\
\text { ADT }\end{array}$ & $\begin{array}{l}\text { Treatment } \\
\text { in control } \\
\text { group }\end{array}$ & $\begin{array}{l}\text { Definition of } \\
\text { CVD }\end{array}$ & ICD code & $\begin{array}{l}\text { No.of CVD } \\
\text { event }\end{array}$ & $\begin{array}{l}\text { No. of } \\
\text { ADT }\end{array}$ & $\begin{array}{l}\text { No. Of } \\
\text { Control }\end{array}$ & $\begin{array}{l}\text { Age } \\
\text { y(median/average) }\end{array}$ \\
\hline Alibhai & 2009 & $\mathrm{ADT}$ & non-ADT & $\mathrm{CHD} / \mathrm{SCD} / \mathrm{HF}$ & $\begin{array}{l}\text { ICD-9-CM } \\
410.0-410.9\end{array}$ & $\begin{array}{l}\text { ADT/Control } \\
3,844 / 4,236\end{array}$ & 19079 & 19079 & 75 \\
\hline Bolla & 2010 & $\begin{array}{l}\text { GnRH } \\
\text { agonist }\end{array}$ & $\begin{array}{l}\mathrm{RP} \\
\text { WW/AS }\end{array}$ & SCD & NA & $22 / 17$ & 107 & 203 & $\begin{array}{l}\text { ADT:71 non- } \\
\text { ADT:70 }\end{array}$ \\
\hline Efstathiou & 2009 & GnRH & $\begin{array}{l}\mathrm{RP} \\
\mathrm{WW} / \mathrm{AS}\end{array}$ & SCD & NA & $52 / 65$ & 477 & 468 & 70 \\
\hline Farrel & 2015 & $\begin{array}{l}\text { AA; GnRH } \\
\text { agonist; } \\
\text { Orchiectomy; } \\
\text { AA GnRH + } \\
\text { AA }\end{array}$ & non-ADT & $\mathrm{CHD} / \mathrm{HF}$ & $\begin{array}{l}\text { ICD-10: I20 } \\
\text { through I25 } \\
\text { (ICD-10: I50 }\end{array}$ & $2,729 / 12,397$ & 41362 & 187785 & $\begin{array}{l}\text { ADT: } 73.7 \text { non- } \\
\text { ADT: } 75.3\end{array}$ \\
\hline Gandaglia & 2014 & $\begin{array}{l}\text { GnRH } \\
\text { agonist; } \\
\text { Orchiectomy }\end{array}$ & non-ADT & CHD/AMI/SCD & ICD-9 & $36,574 / 44,650$ & 59994 & 82535 & $\begin{array}{l}\text { median: } 73 \\
\text { average: } 73.6\end{array}$ \\
\hline $\begin{array}{l}\text { Haque } \\
\text { Hemelriick }\end{array}$ & $\begin{array}{l}2017 \\
2010\end{array}$ & $\mathrm{ADT}$ & $\begin{array}{l}\text { non-ADT } \\
\text { RP }\end{array}$ & $\mathrm{CHD} / \mathrm{AMI} / \mathrm{HF}$ & ICD-9/ICD-10 & $559 / 1111$ & 2170 & $\begin{array}{l}5457 \\
45958\end{array}$ & NR \\
\hline & & $\begin{array}{l}\text { agonist; AA } \\
\text { GnRH + AA; } \\
\text { Orchiectomy }\end{array}$ & WW/AS & & through I25 & & & & \\
\hline Iversen & 2010 & $\mathrm{AA}$ & non-ADT & $\mathrm{AMI} / \mathrm{HF}$ & NA & $163 / 132$ & 4052 & 4061 & 64.5 \\
\hline Jespersen & 2013 & $\begin{array}{l}\text { GnRH/AA; } \\
\text { Orchiectomy }\end{array}$ & non-ADT & AMI & $\begin{array}{l}\text { ICD-8 codes } \\
410.09 / 410.99 \\
\text { and IDC-10 } \\
\text { codes DI21.x }\end{array}$ & $573 / 824$ & 11264 & 20307 & 71 \\
\hline Keating & 2009 & $\begin{array}{l}\text { GnRH } \\
\text { agonist AA; } \\
\text { GnRH + AA; } \\
\text { Orchiectomy }\end{array}$ & WW/AS & CHD/AMI/SCD & $\begin{array}{l}\text { ICD-9 codes } \\
411-414.9 \\
\text { except } 414.1 \mathrm{X}\end{array}$ & $3,031 / 2,223$ & 14579 & 22846 & 66.9 \\
\hline Merino & 2011 & $\begin{array}{l}\text { GnRH } \\
\text { agonist AA; } \\
\text { GnRH + AA; } \\
\text { Orchiectomy }\end{array}$ & WW/AS & $\mathrm{CHD} / \mathrm{AMI} / \mathrm{HF}$ & NA & $197 / 201$ & 406 & 594 & 51 \\
\hline Robinson & 2010 & $\begin{array}{l}\text { GnRH } \\
\text { agonist; AA; } \\
\text { GnRH + AA }\end{array}$ & non-ADT & CHD & ICD10:I20-25 & $370 / 1159$ & 8168 & 30883 & NR \\
\hline Roach & 2008 & $\begin{array}{l}\text { GnRH } \\
\text { agonist AA }\end{array}$ & $\begin{array}{l}\text { RP } \\
\text { WW/AS }\end{array}$ & SCD & NA & $31 / 26$ & 224 & 232 & 70 \\
\hline
\end{tabular}

\section{Figures}




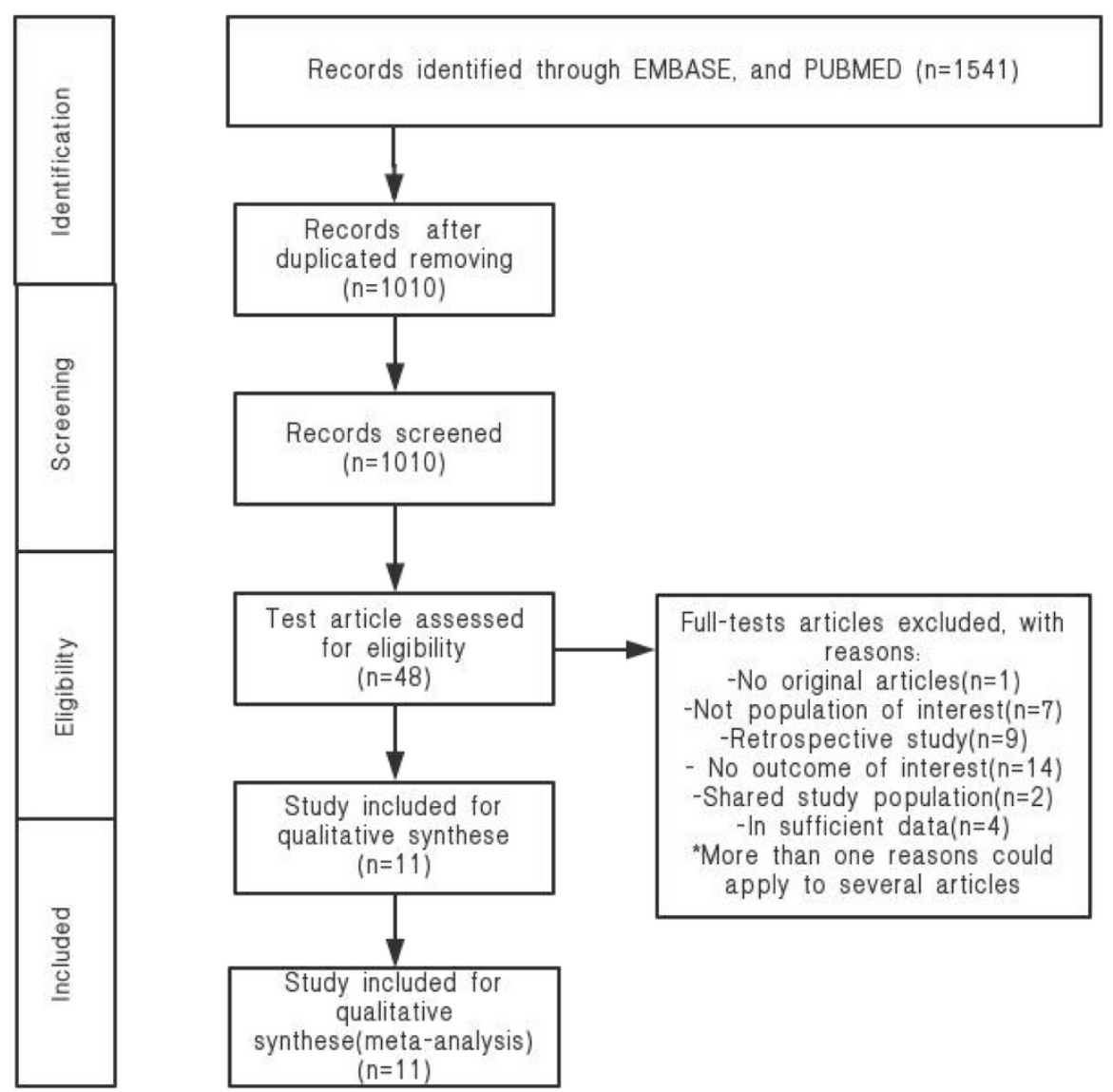

Figure 1

Article selection

Random sequence generation (selection bias)

Allocation concealment (selection bias)

Blinding of participants and personnel (performance bias)

Blinding of outcome assessment (detection bias)

Incomplete outcome data (attrition bias)

Selective reporting (reporting bias)

Other bias
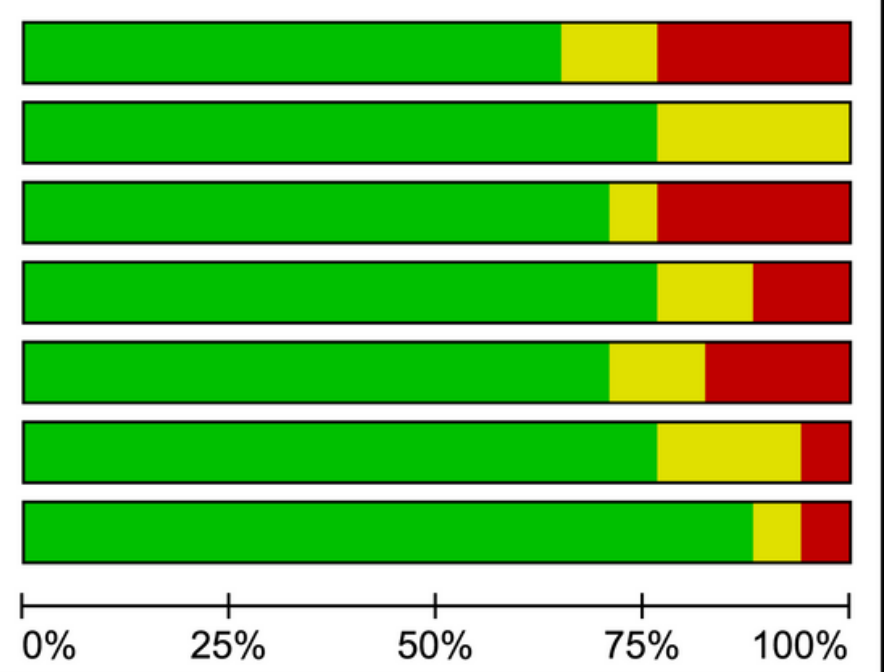

Low risk of bias Unclear risk of bias

High risk of bias 


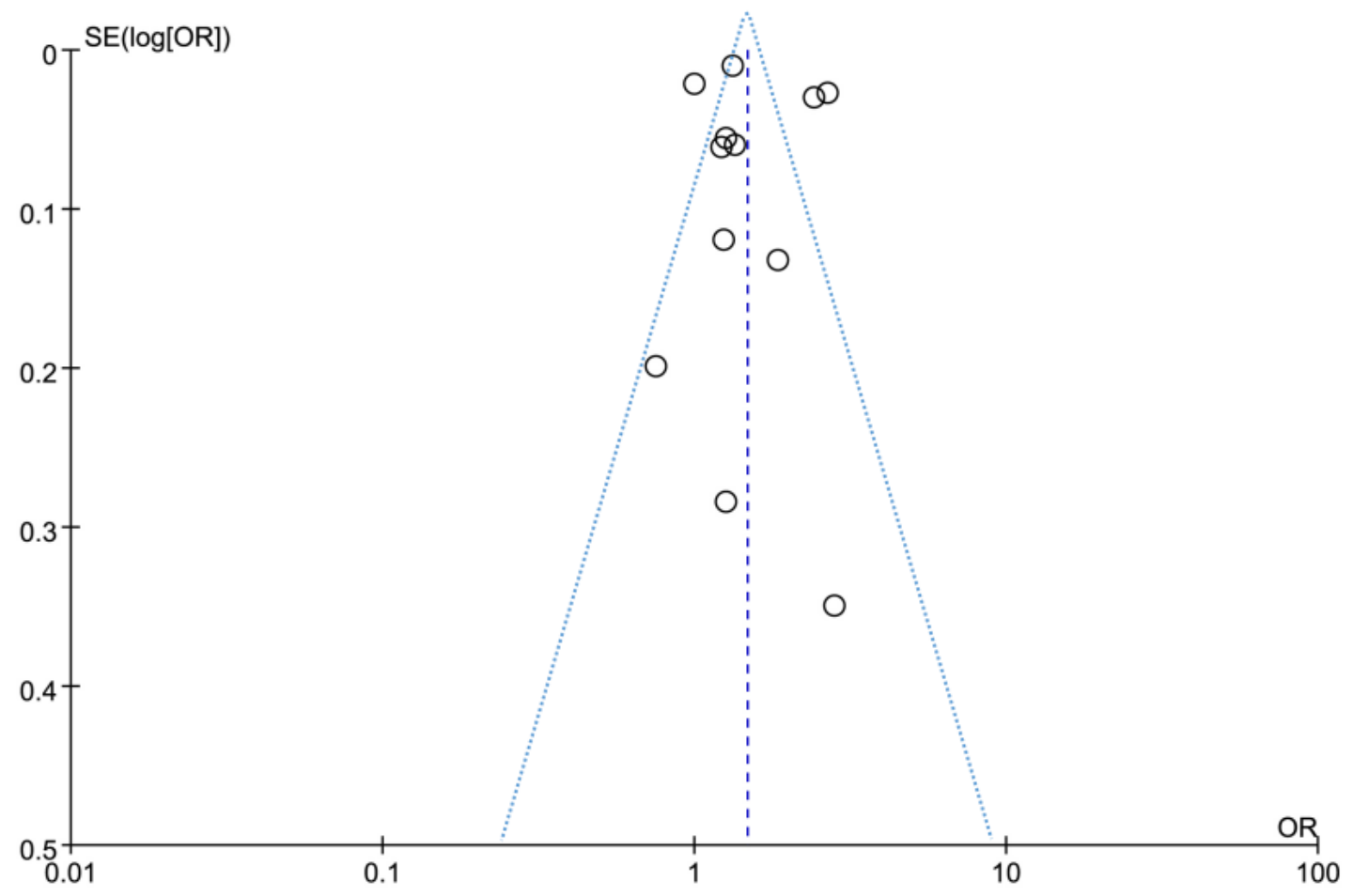

figure 3

Figure 3

Funnel plot to assess publication bias

\section{Experimental Control Risk Ratio}

Study or Subgroup

Alibhai 2009

Gandaglia 2014

Haque 2017

Hemelrijck 2010

Iversen 2010

Jespersen 2014

Keating 2009

Merino 2011

Total $(95 \% \mathrm{Cl})$

Total events

Heterogeneity: $\mathrm{Tau}^{2}=0.04 ; \mathrm{Chi}^{2}=135.50, \mathrm{df}=7(\mathrm{P}<0.00001) ; \mathrm{I}^{2}=95 \%$

Test for overall effect: $Z=2.51(P=0.01)$
Total Weight M-H, Random, 95\% C

$0.87[0.80,0.95]$

$1.12[1.09,1.14]$

$1.20[0.98,1.46]$

$1.05[0.95,1.17]$

$1.21[0.91,1.61]$

$1.25[1.13,1.39]$

$2.07[1.83,2.34]$

$1.40[0.95,2.05]$

$1.22[1.05,1.43]$
Risk Ratio

M-H, Random, $95 \% \mathrm{Cl}$

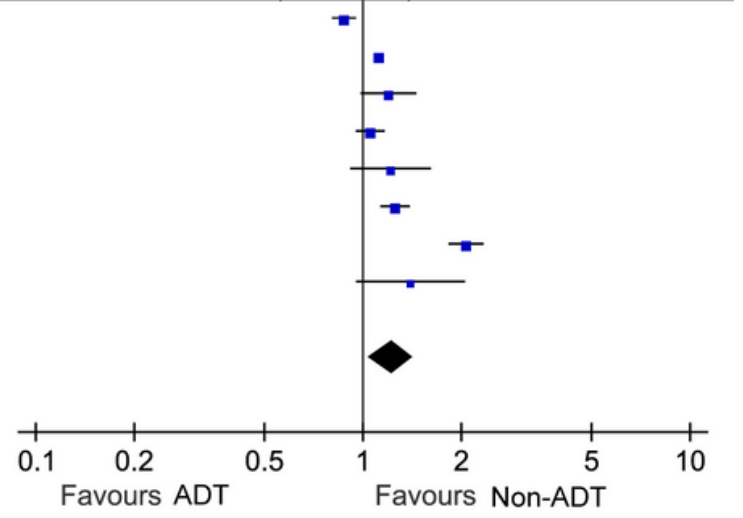

Figure 4

Figure 4

Acute myocardial infarction risk associated with $A D T$ 


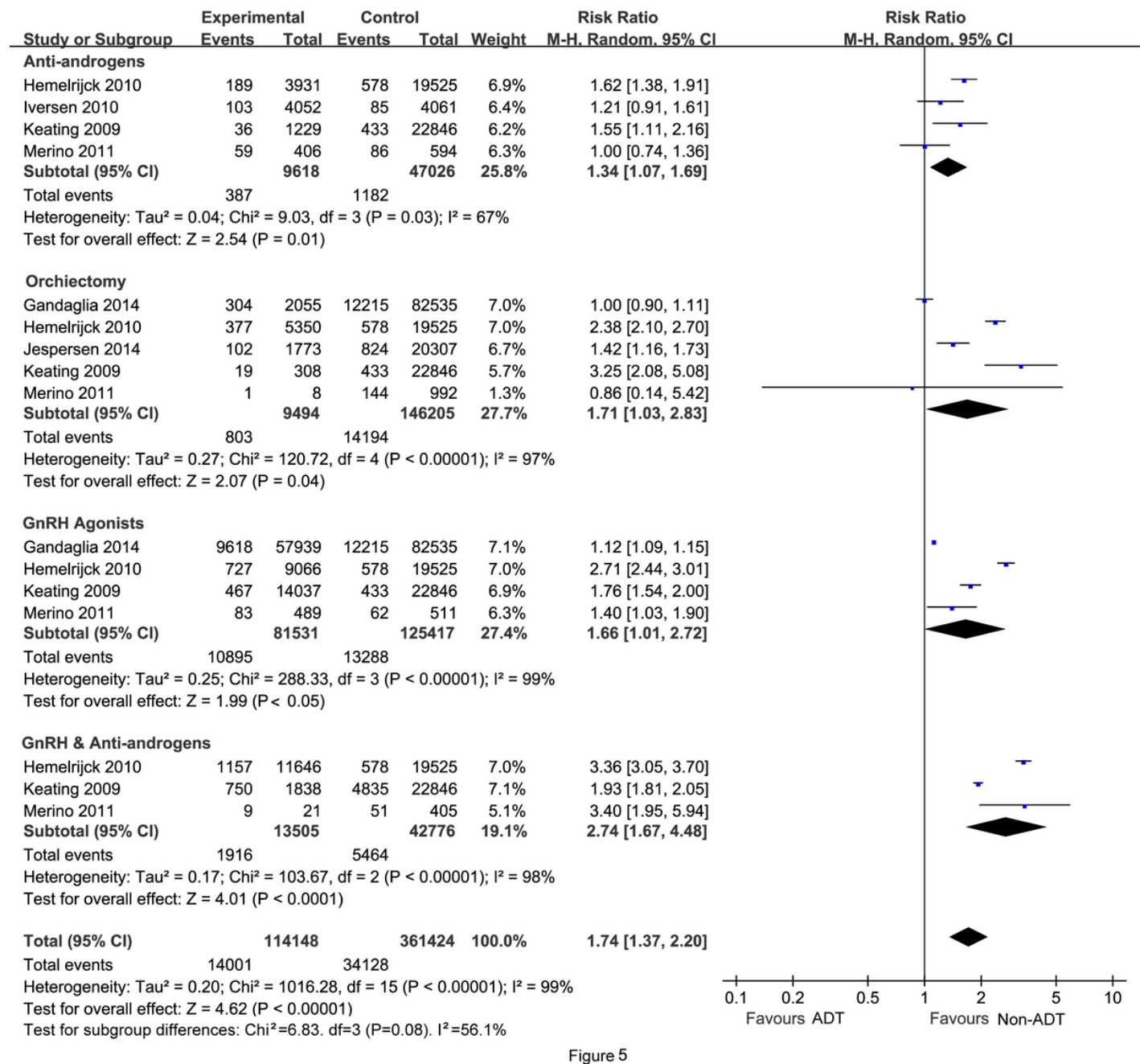

\section{Figure 5}

RRs of acute myocardial infarction related to different types of ADT. 


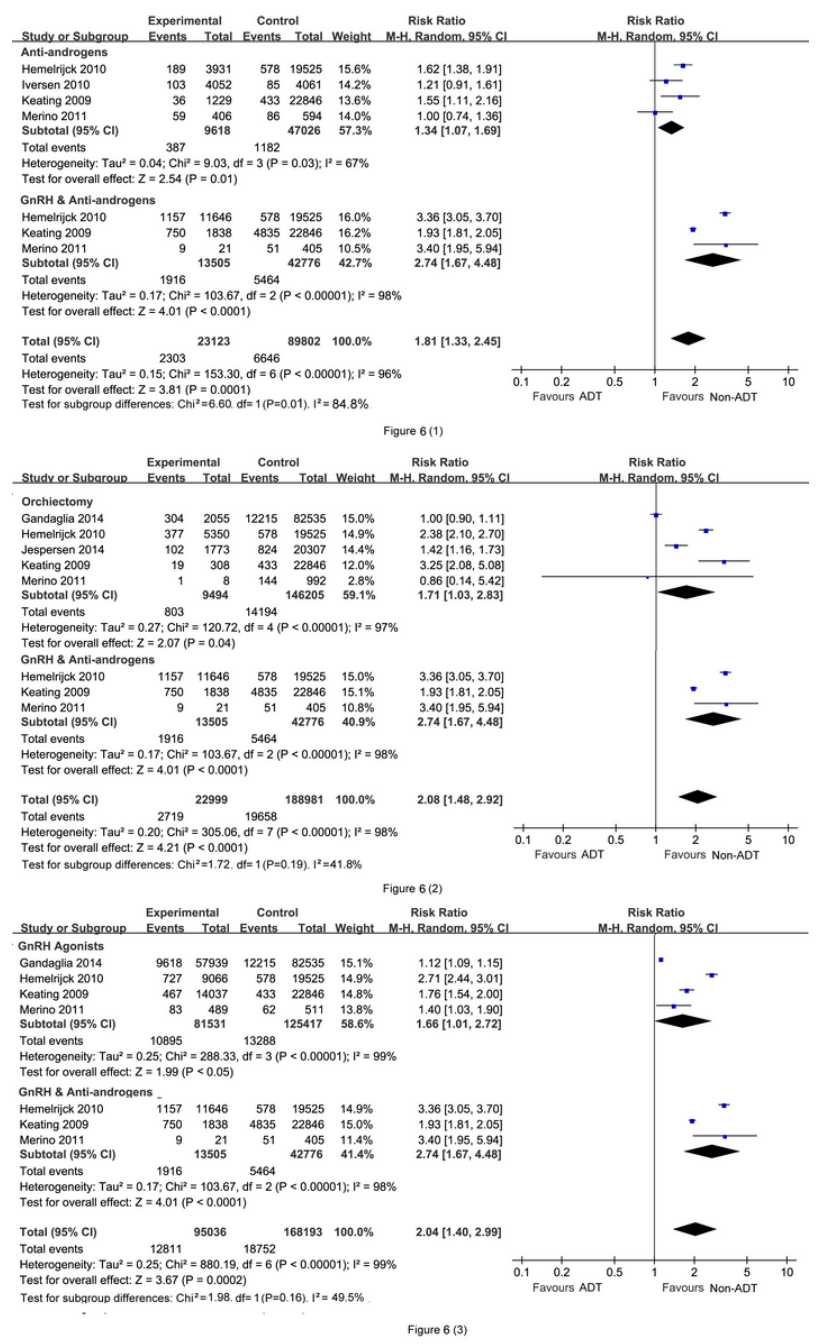

Figure 6

GnRH agonists plus AA compared with other method for acute myocardial infarction

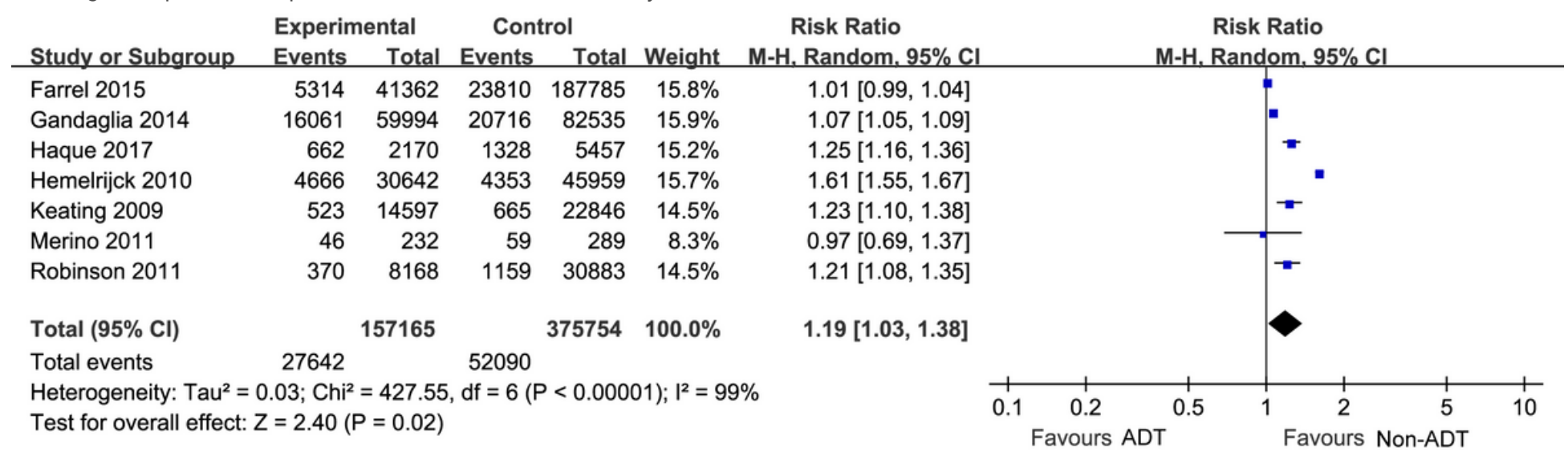

Figure 7

Figure 7

Coronary heart disease risk associated with ADT 


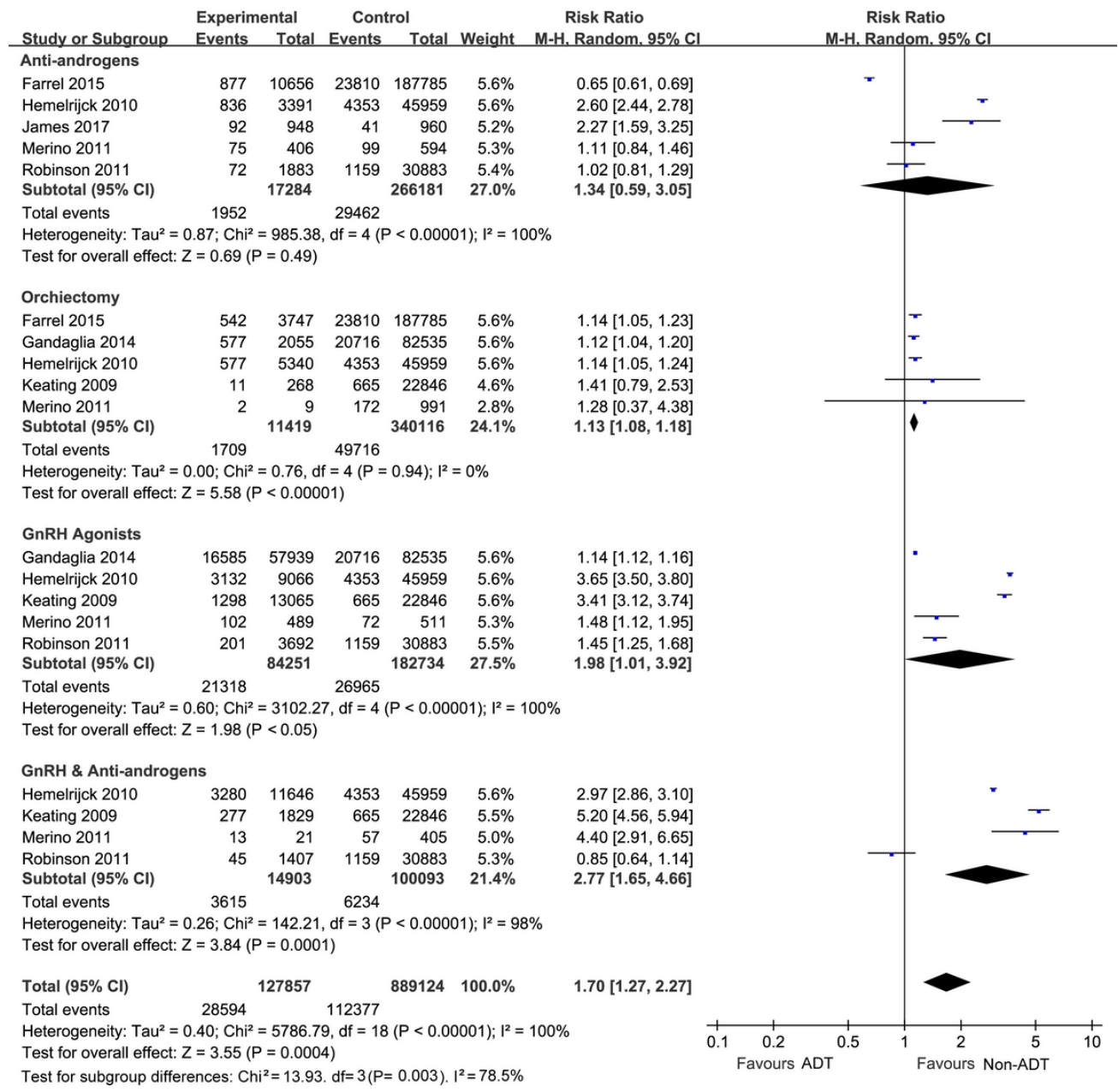

Figure 8

\section{Figure 8}

RRs of coronary heart disease related to different types of ADT. 


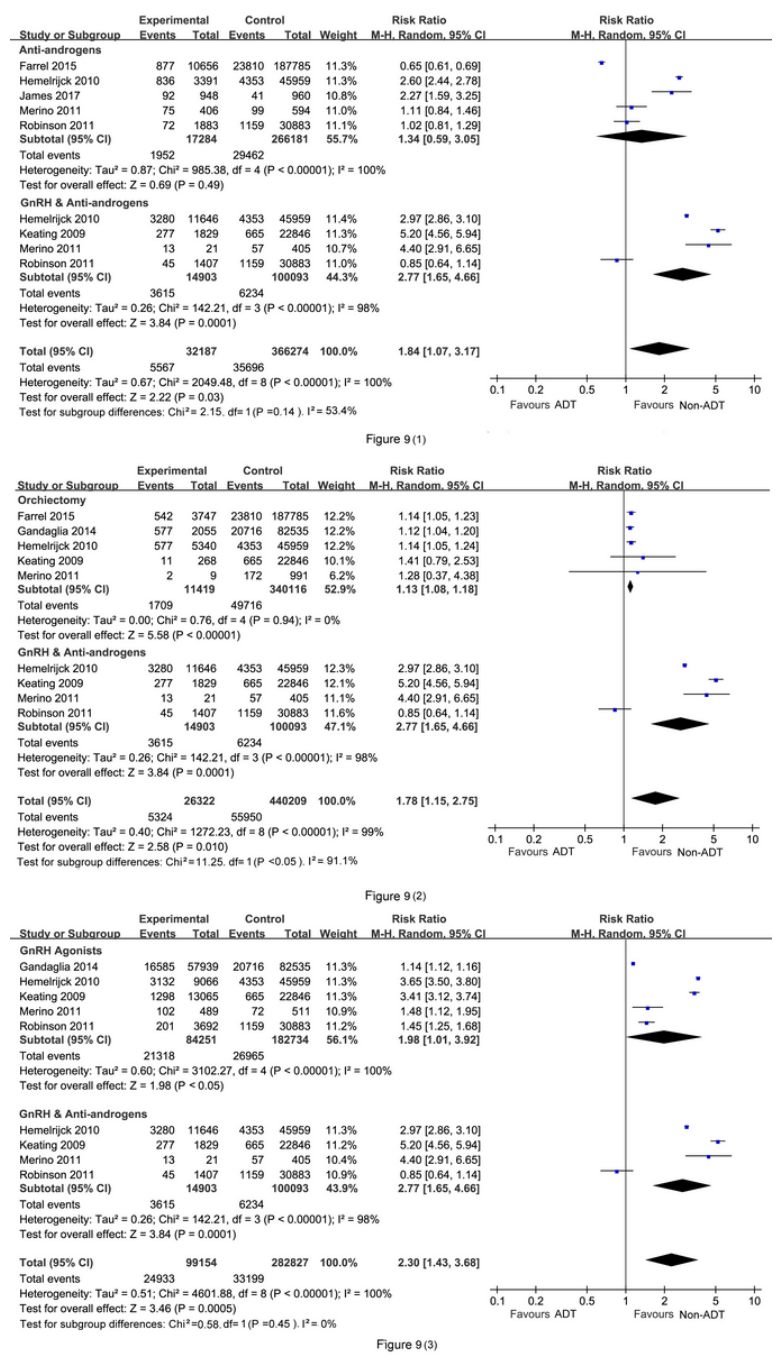

Figure 9

GnRH agonists plus AA compared with other method for coronary heart disease

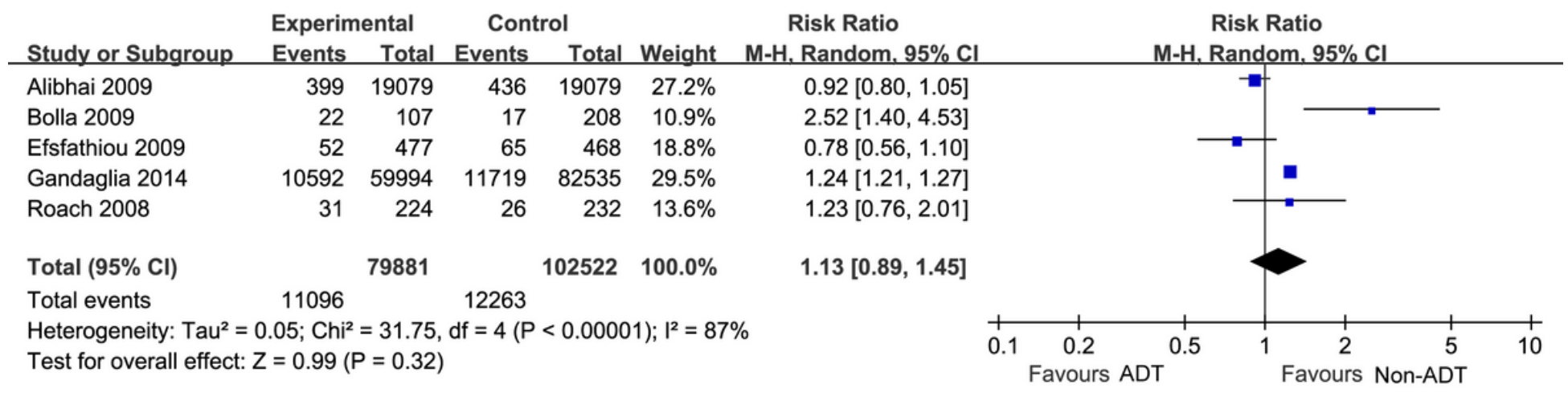

Figure 10

Figure 10

Sudden cardiac death risk associated with ADT 


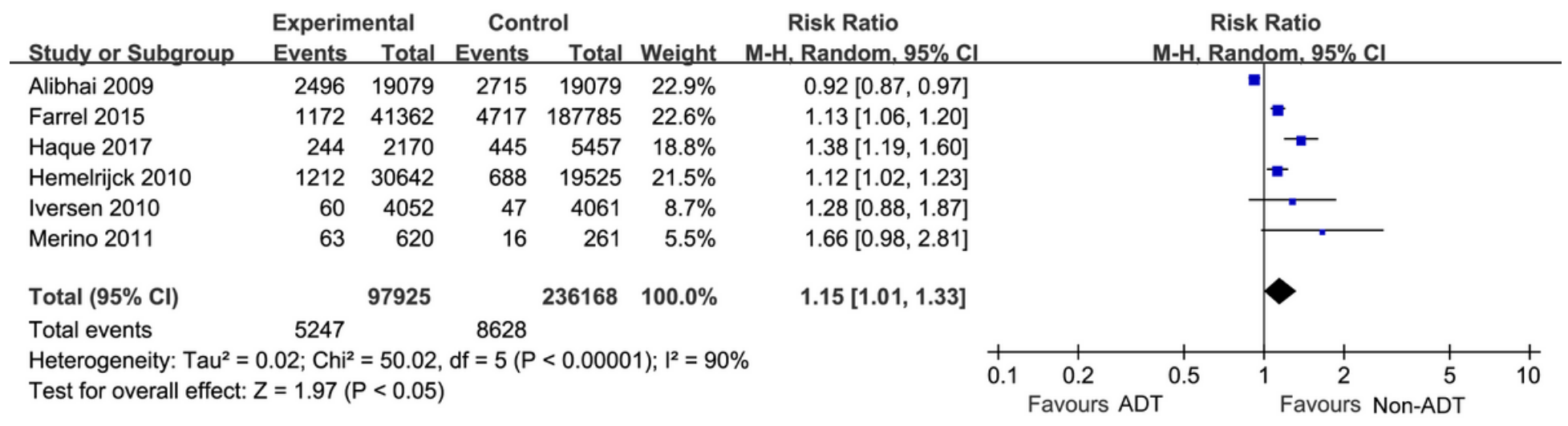

Figure 11

Figure 11

Heart failure risk associated with ADT

Experimenta

Control

Risk Ratio

Risk Ratio

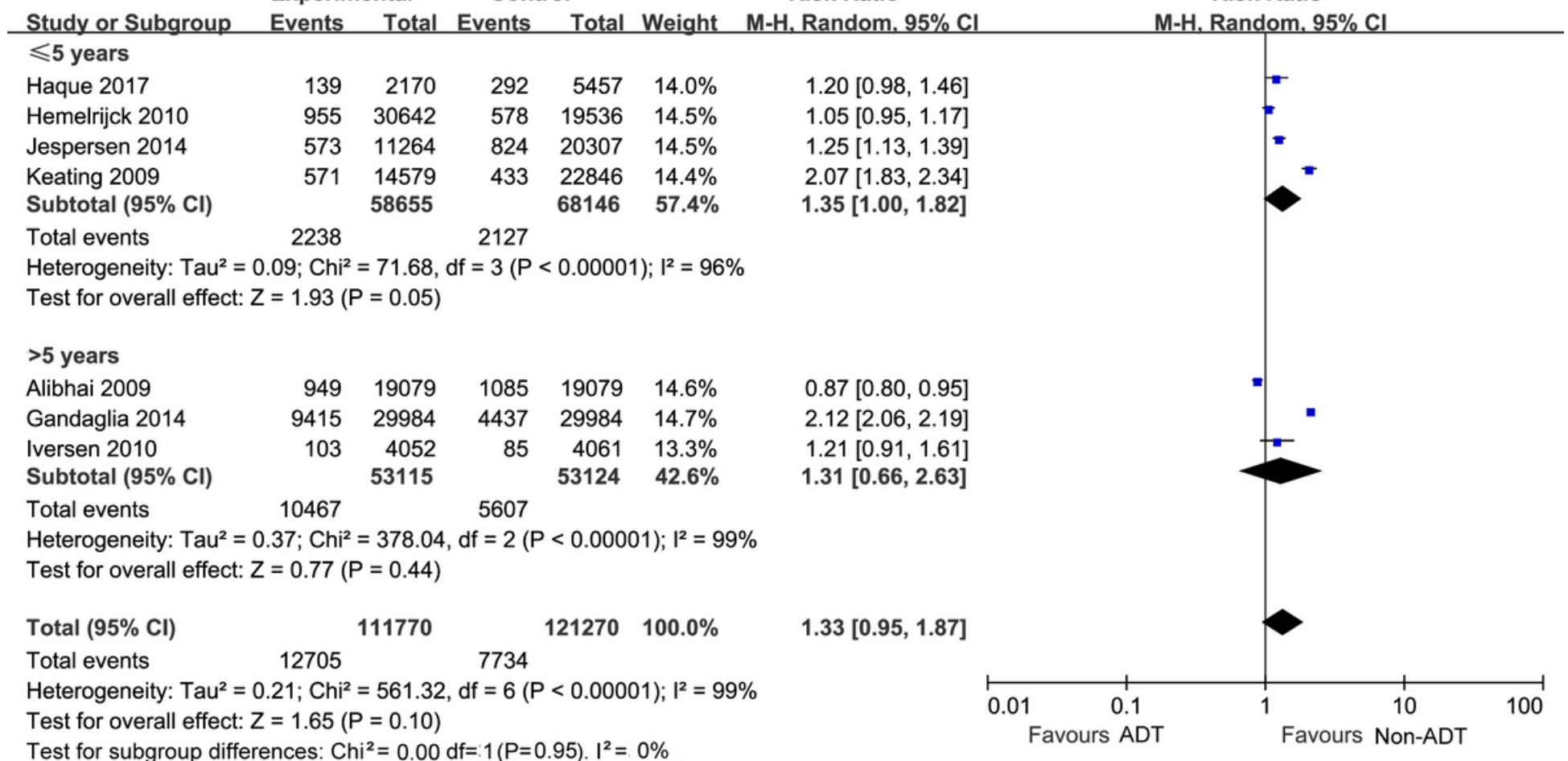

Figure 12

Figure 12

RRs of acute myocardial infarction related to different duration of ADT application. 